\title{
Numerical Simulation of High Pressure Hydrogen Release through an Expanding Opening

\author{
Reza Khaksarfard ${ }^{1}$, Marius Paraschivoiu ${ }^{{ }^{*}}$
}

${ }^{1}$ Department of Mechanical and Industrial Engineering, Concordia University, 1455de Maisonneuve West, Montreal, Quebec, H3G 1M8, Canada

*Corresponding author

Department of Mechanical and Industrial Engineering, Concordia University, 1455de Maisonneuve West, Montreal, Quebec, H3G 1M8, Canada

Paraschi@encs.concordia.ca

Tel 1-514-848-2424 ext. 3147

Fax 1-514-848-3175 


\begin{abstract}
Computational Fluid Dynamics is an effective tool to develop safety standards related to the sudden release of hydrogen from a high pressure reservoir. In this work, a threedimensional in-house code is developed to numerically simulate the release of high pressure hydrogen $(70 \mathrm{MPa}$ ) from a reservoir when the release area into air is expanding with time. Furthermore, high pressure hydrogen flows cannot be accurately simulated by the ideal gas equation; therefore the Abel-Noble real gas equation of state is applied. A transport equation is solved to find the concentration of hydrogen and air in the hydrogenair mixture generated soon after release. The novelty of this work is to simulate and to study the flow when the release area enlarges rapidly. To obtain this capability, the solid boundaries of the release area are moved and the mesh follows based on a spring method. All the nodes in the mesh are moved at each time step accordingly to have a good quality mesh. Three initial diameters of $1.0 \mathrm{~mm}, 1.5 \mathrm{~mm}$ and $2.0 \mathrm{~mm}$ are tested for the release area, and opening wall speeds of $80 \mathrm{~m} / \mathrm{s}$ and up to $300 \mathrm{~m} / \mathrm{s}$ are discussed.
\end{abstract}

Keywords: Hydrogen, expanding nozzle flow, Moving Mesh, Real gas, Abel-Noble

\title{
1-Introduction
}

The low energy content per unit volume is the main drawback of using hydrogen as a fuel. Therefore, hydrogen has to be stored in high pressure tanks (up to $70 \mathrm{MPa}$ ) to provide enough energy storage. The high pressure ratio of the storage tank to the ambient pressure results in a highly under-expanded jet in case of a rupture or a connector failure. Hydrogen may ignite after release as in the incidents of the Stockholm explosion [1]. Nevertheless, spontaneous ignition does not always occur and predicting ignition of hydrogen still requires more research [2]. Ignition based on the diffusion ignition mechanism was first shown experimental by Wolański and Wójcicki [3]. Golub et al. [4] also studied experimentally the spontaneous ignition of hydrogen release through a tube of cross section area of $20 \mathrm{~mm}^{2}$ into a semi-confined space. Both round and rectangular cross sections were tested. The hydrogen pressure in the chamber was increased up to $10 \mathrm{MPa}$. It was concluded that the ignition is probable if the chamber pressure is higher than $4 \mathrm{MPa}$. More experimental results were reported in the work of Shirvill et al. [5] where the maximum release pressure was $13 \mathrm{MPa}$ and hydrogen was released from a circular orifice of 3mm diameter. Numerical simulations were also performed to capture spontaneous ignition of hydrogen within a tube after the rupture of a disk at a bursting pressure of 8.7 MPa [6]. 
Understanding the critical features of the hydrogen-air mixture and the flow pattern for higher release pressure is important as storage reservoirs of $70 \mathrm{MPa}$ are considered. Khaksarfard et al. [7] numerically simulated the release from a high pressure reservoir (up to $70 \mathrm{MPa}$ ) using a three dimensional in-house code based on tetrahedral elements. The Abel-Noble equation was used as the real gas model [8] and results were compared to the ideal gas results. The exit diameter was $5 \mathrm{~mm}$ and both the reservoir and the external environment were included in the computational domain. Liu et al. [9] used a direct numerical simulation to investigate the jet exiting from tanks with pressure of 10, 40 and $70 \mathrm{MPa}$, and exit diameter of $1 \mathrm{~mm}$. In their work, two dimensional Euler axisymmetric equations were applied and the stagnation pressure was $300 \mathrm{~K}$. Ignition and combustion mechanism were also included and it was concluded that an ignition source is needed to have a hydrogen flame. Radulescu et al. [10] numerically simulated highly under-expanded jets from both slit and round orifices. In their work, the ideal gas law and two dimensional axisymmetric equations were used. The pressure ratio of the tank to the external environment was in the range of 100 to 1000. Viscous effects were only considered in areas of high gradients since the Reynolds number is high. In regions of low gradients, the results were similar to the results of Euler equations.

Since high pressure hydrogen can not be accurately simulated by the ideal gas equation, a real gas equation of state is necessary to accurately find out the critical features of the flow. There are several real gas equations of state; amongst them the Abel-Noble which has one constant, the Van der Waals, the RedlichKwong, the Dieterici and the Berthelot which have two constants, and the Beattie-Bridgeman, the Clausius and the Wohl which have three constants. Cheng et al. [11] investigated the release through an exit area with a $6 \mathrm{~mm}$ diameter using the Abel-Noble equation of state for reservoirs with pressure of up to $40 \mathrm{MPa}$. Their results showed considerable difference between ideal gas and real gas models. This difference increased, as expected, for higher tank pressures. In their research, the flow was analysed after a long release time in the order of seconds, therefore they did not investigate the flow near the jet exit. Their work reported that the mass flow rate is overestimated by 30\% in the first 10 seconds and 35\% in the first 25 seconds of release for the ideal gas model compared to the real gas model. Mohamed et al. [12] simulated the release from a tank of $34.5 \mathrm{MPa}$ using Beattie-Bridgeman state equation. In their work, the external environment was not included; only the chamber with an exit boundary was considered for the calculations. Analytical results were compared with numerical results. They showed that there is only 2 percents difference between analytical and numerical results, and the exit velocity is 14 percents higher when using a real gas at the beginning of release. 
In most practical cases the release area expands in time so this paper describes the effect of this geometry change on the flow. To this end a moving mesh is developed for our in-house code. Euler equations are changed according to the work of Trepanier et al. [13] in which the velocities are changed to the relative velocity considering the speed of each node while moving. The movement method uses a basic springbased method explained in the work of Zhang et al. [14] and Zenga et al. [14]. In this method each edge acts as a spring and the nodes are moved based the force calculated by Hook’s law.

As in the case of a fixed exit area, hydrogen releases into air very rapidly and strong shocks happen soon after release. These shocks and flow pattern were previous discussed by the authors for a fixed mesh and for longer time of up to 110 micro seconds after release [7]. The objective of this work is to focus on the very first few micro seconds after release and on an expanding release area. The Abel-Noble real gas equation of state is applied since the ideal gas equation cannot accurately simulate the high pressure hydrogen. The code uses parallel processing to access large memory and to reduce the solution time. Hydrogen is release into air, therefore soon after release a hydrogen-air mixture is generated. A transport equation is used to find out the concentration of hydrogen and air in the mixture. Euler equations are used to solve this high Reynolds number flow as viscous effects are negligible in the near jet exit area. Euler equations and transport equation are changed for the moving mesh feature. The code is based on an implicit scheme, second order accuracy in space and first order accuracy in time. In the literature, we only found one paper [16] describing the flow of air in an expanding nozzle.

In this paper, first the governing equations for the moving mesh and the Abel-Noble real gas equation are explained. Then the spring-based mesh moving method is discussed. The geometry and the meshes used for the simulation are reported. Finally the results of the flow simulation for the release of hydrogen from a 70 MPa tank into ambient air are presented. Three initial exit diameters of $1.0 \mathrm{~mm}, 1.5 \mathrm{~mm}$ and $2.0 \mathrm{~mm}$, and three opening speed of $100 \mathrm{~m} / \mathrm{s}, 200 \mathrm{~m} / \mathrm{s}$ and $300 \mathrm{~m} / \mathrm{s}$ are investigated.

\section{2-Governing Equations}

\section{2-1-Euler Equations and Discretization}

This high Reynolds number flow can be simulated by solving the Euler equation in the vicinity of the exit. The Euler equation is solved according to the [13] for the moving mesh:

$$
\frac{\partial U}{\partial t}+\nabla \cdot F=0
$$

where,

$$
U=\left[\begin{array}{c}
\rho \\
\rho u_{x} \\
\rho u_{y} \\
\rho u_{z} \\
\rho E
\end{array}\right] \quad, \quad F=\left\{\left[\begin{array}{c}
\rho\left(u_{x}-w_{x}\right) \\
\rho\left(u_{x}-w_{x}\right) u_{x}+P \\
\rho\left(u_{x}-w_{x}\right) u_{y} \\
\rho\left(u_{x}-w_{x}\right) u_{z} \\
\rho\left(u_{x}-w_{x}\right) E+u_{x} P
\end{array}\right]\left[\begin{array}{c}
\rho\left(u_{y}-w_{y}\right) \\
\rho\left(u_{y}-w_{y}\right) u_{y} \\
\rho\left(u_{y}-w_{y}\right) u_{y}+P \\
\rho\left(u_{y}-w_{y}\right) u_{z} \\
\rho\left(u_{y}-w_{y}\right) E+u_{y} P
\end{array}\right]\left[\begin{array}{c}
\rho\left(u_{z}-w_{z}\right) \\
\rho\left(u_{z}-w_{z}\right) u_{x} \\
\rho\left(u_{z}-w_{z}\right) u_{y} \\
\rho\left(u_{z}-w_{z}\right) u_{z}+P \\
\rho\left(u_{z}-w_{z}\right) E+u_{z} P
\end{array}\right]\right\}
$$


$w_{x}, w_{y}$ and $w_{z}$ are the node speeds in each coordinate direction. In our simulation, boundary nodes are moved radially in order to enlarge the exit with a fixed speed. The other inner nodes are moved to maintain a good mesh quality as described in section 3. The following equation is used for discretization:

$\frac{U^{n+1} V^{n+1}-U^{n} V^{n}}{\Delta t}+\sum_{\text {surface }} F^{n+1} \cdot n \Delta A=0$

where $V^{n}$ and $V^{n+1}$ are the volume of the control volume before and after movement in each time step.

\section{2-2-Transport Equation}

A transport equation is added to calculate the concentration of Hydrogen and air in the hydrogen-air mixture. The transport equation previously used by the authors [7] is modified according to the moving speed:

$\frac{\partial(\rho c)}{\partial t}+\frac{\partial\left(\rho c\left(u_{x}-w_{x}\right)\right)}{\partial x}+\frac{\partial\left(\rho c\left(u_{y}-w_{y}\right)\right)}{\partial y}+\frac{\partial\left(\rho c\left(u_{z}-w_{z}\right)\right)}{\partial z}=0$

The air concentration is given by $c$ which varies between zero and one, and is one in locations of no hydrogen. Therefore, $c$ is initially zero in the tank and one in the external environment. This transport equation is solved at the end of each time step. Finally, $R$ of the mixture at each time step is calculated based on the concentration $c$ :

$R_{\text {mix }}=R_{\mathrm{H}_{2}}(1-c)+R_{\text {Air }} \mathrm{C}$

where $R_{\mathrm{H}_{2}}=4124 \mathrm{~J} / \mathrm{kgK}$ and $R_{\text {Air }}=287 \mathrm{~J} / \mathrm{kgK}$

\section{2-3-Real Gas Equation}

The Abel-Noble real gas equation is applied as the state equation since the ideal gas equation is not capable of accurately simulating high pressure hydrogen. The Abel-Noble equation uses a compressibility factor $z$ compared to the ideal gas equation ( $P=\rho R T$ ) which is a function of density and a constant $b$ :

$$
P=\frac{R T}{(v-b)}=\frac{\rho R T}{(1-b \rho)}=(1-b \rho)^{-1} \rho R T=z \rho R T \quad, \quad b=0.00775 \mathrm{~m}^{3} / \mathrm{kg}
$$


The difference between ideal gas and Abel-Noble equations can be neglected up to a pressure of $10 \mathrm{MPa}$ but for higher pressures the ideal gas modelling cannot give accurate results.

\section{3-Spring-Based Mesh Moving}

The mesh is moved by using the spring-based method [14, 15]. In this method the boundary nodes are moved at each time step and the interior nodes are moved accordingly to reach the equilibrium state in the entire domain. Each edge acts like a spring such that the movement of a boundary node generates a force along the connected edges. The total force on one node is the sum of all these forces. This force is calculated by Hook’s law:

$F=\sum k_{i}\left(\Delta x_{i}-\Delta x\right)$

where $\Delta x$ is the displacement of the node and $\Delta x_{i}$ is the displacement of the neighbouring nodes. $k_{i}$

is the stiffness of each connected edge and is found as follow:

$k_{i}=\frac{1}{\text { Edge Length }}$

The total force on each node should be zero at the equilibrium state. Therefore $\Delta x$ of each node is found by solving the following iterative equation:

$\Delta x=\frac{\sum k_{i} \Delta x_{i}}{\sum k_{i}}$

The new position of each node is finally obtained by adding $\Delta x$ to the previous position of the node:

$x^{n+1}=x^{n}+\Delta x$

\section{4-Geometry and Mesh}

The three-dimensional geometry consists of a reservoir, a release area and an external environment. High pressure hydrogen is released from the reservoir through the release area into the external environment. The domain is cylindrical. In Figure (1) a three-dimensional view and a two-dimensional cut of the geometry and mesh are given. The geometry and the three-dimensional tetrahedral mesh are generated with Gambit. Three meshes are constructed of size: 0.8 million nodes, two million and three million nodes to evaluate the impact of the mesh size on the accuracy of the results. The mesh shown in Figure (1) contains 0.8 million nodes. The finer meshes are not shown since higher concentration of nodes cannot be visible in a small figure. Parallel processing is used and the mesh is divided into 32 partitions. The external environment is 
small compared to the reservoir and compared to the external environment previously used by the authors to simulate the flow through a fixed diameter release area since the focus in this work is on the first three micro seconds after release. Three initial diameters of $1.0 \mathrm{~mm}, 1.5 \mathrm{~mm}$ and $2.0 \mathrm{~mm}$ are studies. The release area is $2.0 \mathrm{~mm}$ long for all cases and the initial interface is in the middle of this release tube.

\section{5-Simulation}

A three-dimensional in-house code using the Abel-Noble real gas equation is developed to simulate the release of high pressure hydrogen into air from a reservoir through an enlarging tube-shaped area. Although in reality the release area is initially closed, this case cannot be tested with the proposed methodology since nodes are not generated during the movement of the mesh, therefore three very small initial release area diameters of $1.0 \mathrm{~mm}, 1.5 \mathrm{~mm}$ and $2.0 \mathrm{~mm}$ are considered. The tank pressure is $70 \mathrm{MPa}$ for all cases and the outside environment has ambient conditions. The initial temperature is $300 \mathrm{~K}$ in the whole domain. The release area length is $2.0 \mathrm{~mm}$ and the initial interface is in the middle of the release tube. The speed of sound of the hydrogen at the exit is approximately $1400 \mathrm{~m} / \mathrm{s}$ therefore it was decided to examine the opening speeds that are an order of magnitude less than the speed of sound. Three opening speeds of 100 $\mathrm{m} / \mathrm{s}, 200 \mathrm{~m} / \mathrm{s}$ and $300 \mathrm{~m} / \mathrm{s}$ are tested for all cases. These speeds refer to the speed of the wall outwards. In Figure (2), the two-dimensional view of the mesh of the release tube at different times of 1.0, 1.5, 2.0, 2.5 and 3.0 micro seconds after release for the initial diameter of $1.0 \mathrm{~mm}$ and an opening speed of $500 \mathrm{~m} / \mathrm{s}$ is presented. The mesh is moved using the spring-based method to maintain a high quality mesh at all steps as seen in the figure.

\section{5-1-Validation}

Results of a fixed opening are used for validation due to the lack of expanding orifice simulation in the literature. Pedro et al. [17] simulate the release using FLUENT from a tank with a pressure of $10 \mathrm{MPa}$. Although in their work the ideal gas equation is employed, results are still accurate enough since the tank pressure is not very high. Figure (3) shows the Mach number along the centerline at different times for both our and theirs computations. It is noticed the difference is negligible. The non-dimensionalize time is based on the diameter of the orifice over the sound speed of hydrogen for a temperature of $300 \mathrm{~K}$.

Another validation approach is based on comparing our results with the analytical work of Ashkenas et al. [18]. They propose an equation to calculate the final location of the Mach disk according to the pressure ratio.

$$
Z / D=0.67\left(P_{0} / P_{1}\right)^{1 / 2}
$$

$\mathrm{Z}$ is the distance from the orifice and $\mathrm{D}$ is the orifice diameter. In table (1), for three different pressures of 10 MPa, 34.5 MPa and 70 MPa this equation is used to compare results of our simulation. Although the 
results of the present simulation show some difference from the results of the analytical equation, this analytical equation is still a good indication that our simulation is adequate.

\section{5-2-Mesh Study}

Three meshes of 0.8, 2.0 and 3.0 million nodes are investigated. Pressure on the contact surface along the center line and the contact surface location for the 0.8 million node mesh and the 2 million node mesh are plotted in Figure (4) for different opening speeds. In Figure (5), results are given for different initial diameters. Results show the 2 million node mesh gives more accurate results. In Figure (6), the 2 and 3 million node meshes are compared in case of an initial diameter of $1 \mathrm{~mm}$ and an opening speed of $80 \mathrm{~m} / \mathrm{s}$. It is concluded that the 2 million node mesh is accurate enough since the difference with the 3 million node mesh is negligible.

\section{5-3 Analysis of the flow}

Soon after release, hydrogen mixes with air and a contact surface is formed. Since the 2 million node mesh is accurate enough, the rest of the results are based on this mesh. The initial time step is $10^{-9}$ seconds and the initial CFL number is 0.3 . CFL is multiplied by 1.0001 before each time iteration. Note that the time step is very small so that the temporal error is very small. In Figure (7), Mach number, concentration, density, pressure and velocity contours are presented after 3 micro seconds. The Mach number increases very rapidly and the flow advances very fast. In Figure (8), Mach number, concentration, density, pressure, velocity and temperature are given along the centerline. The maximum Mach number reaches almost 6 and the maximum velocity reaches almost $3000 \mathrm{~m} / \mathrm{s}$. We note from Figure (7b) and (8b) that some hydrogen is entrapped in front of the lead shock. This flow feature was also noticed for a fixed exit orifice.

The hydrogen-air mixture ahead of the contact surface has the potential to ignite since temperature may rise up to the temperature required for ignition and also air exists in the mixture. Properties on the contact surface along the centerline are important to predict ignition. If there is a possibility of explosion it certainly occurs ahead of the contact surface where the mixture is heated by the lead shock. Since combustion models need the value of pressure on the contact surface as an input, the following results mainly discuss the pressure on the contact surface along the centerline. In Figure (9a), the pressure versus time along the centerline on the contact surface is presented for the initial diameter of $1.0 \mathrm{~mm}$ for a fixed mesh and opening speeds of $100 \mathrm{~m} / \mathrm{s}, 200 \mathrm{~m} / \mathrm{s}$ and $300 \mathrm{~m} / \mathrm{s}$ and in Figure (9b) the contact surface location as a function of time is reported. The pressure on the contact surface is sensitive to the opening speed. For 
example, the pressure is approximately 3.0 MPa for the opening speed of $300 \mathrm{~m} / \mathrm{s}$ while it is approximately 5.0 MPa for the opening speed of $100 \mathrm{~m} / \mathrm{s}$ after 0.3 micro seconds. The major difference is in the first micro second. A slight difference is also noticed in the contact surface location by changing the opening speed.

To find out the effect of the initial release area diameter, for the opening speed of $200 \mathrm{~m} / \mathrm{s}$, the pressure and the contact surface location versus time are given in Figure (10) for an initial release area diameters of 1.0 $\mathrm{mm}, 1.5 \mathrm{~mm}$ and $2.0 \mathrm{~mm}$. The value of pressure is higher for larger diameters and the difference is not negligible. The contact surface location is similar for all cases up to the time of 2.0 micro seconds. The flow advances faster for larger diameter after 2.0 micro seconds.

As mentioned earlier and noticed in Figures (7b) and (8b), hydrogen is trapped ahead of the flow after a certain time. In Figure (11), the concentration is given at very early times of 0.2, 0.4, 0.6 and 0.8 micro seconds after release to find out how hydrogen is trapped and how air seperates the trapped hydrogen from the head of the contact surface.

\section{6- Conclusion}

An in-house parallel code is developed to simulate the release of high pressure hydrogen into air through an enlarging tube-shaped exit. The Abel-Noble real gas equation is applied to accurately simulate the release since high pressure hydrogen deviates from the ideal gas law. A transport equation is added to find out the concentration of hydrogen and air in the mixture. A spring-based method is applied to move the mesh nodes and the Euler equation is modified to consider the mesh movement. Three initial diameters of $1.0 \mathrm{~mm}, 1.5$ $\mathrm{mm}$ and $2.0 \mathrm{~mm}$ are investigated and three opening speeds of $100 \mathrm{~m} / \mathrm{s}, 200 \mathrm{~m} / \mathrm{s}$ and $300 \mathrm{~m} / \mathrm{s}$ are studied. It is seen that the first few micro seconds after release are important for ignition prediction. It is concluded that the pressure on the contact surface which is important for combustion models depends on both the initial diameter and opening speed, and also the pressure drops faster when the release area opens faster.

\section{Acknowledgement}

The authors would like to thank NSERC Hydrogen Canada (H2CAN) Strategic Research Network. 


\section{References}

1. Venetsanos AG, Huld T, Adams P, Bartzis JG. Source, dispesion and combustion modeling of an accidental release of hydrogen in an urban environment. J Hazard Mater 2003; A105: 1-25.

2. Astbury GR, Hawksworth SJ. Spontaneous Ignition of Hydrogen Leaks: A Review of Postulated Mechanisms. Int J Hydrog Energy 2007; 32: 2178-85.

3. Wolanski, P. and Wojcicki, S., Investigation into the Mechanism of the Diffusion Ignition of a Combustible Gas Flowing into an Oxidizing Atmosphere, Proc Combust Inst, 1973; 14: 12171223

4. Golub VV, Baklanov DI, Bazhenova TV, Golovastov SV, Ivanov MF, Laskin IN et al.. Experimental and numerical investigation of hydrogen gas auto-ignition. Int J Hydrog Energy 2009; 34: 5946-53.

5. Shirvill LC, Roberts P, Butler CJ, Roberts TA, Royle M. Characterisation of the hazards from jet releases of hydrogen. Proceedings of International Conference on Hydrogen Safety; 2005 Sep 8-10; Pisa, Italy.

6. Lee B.J. and Jeung I.-S. Numerical Study of Spontaneous Ignition of Pressurized Hydrogen Release by the Failure of a Rapture Disk into a Tube. Int J Hydrog Energy 2009; 34: 8763-8769.

7. Khaksarfard R, Kameshki MR, Paraschivoiu M. Numerical simulation of high pressure release and dispersion of hydrogen into air with real gas model. Shock Waves -Int J Shock Waves, Detonations and Explos 2010; 20: 205-16.

8. Chenoweth DR, Paolucci S. Compressible flow of a two-phase fluid between finite vessels-II, AbelNoble carrier gas. Int J Multiphase Flow 1993; 18: 669-89.

9. Liu YF, Tsuboi N, Sato H, Higashino F, Hayashi AK. Direct numerical simulation on hydrogen fuel jetting from high pressure tank. Proceedings of the 20th international colloquium on the dynamics of explosions and reacting systems; 2005; Montreal, Canada.

10. Radulescu MI, Law CK. The transient start of supersonic jets. J Fluid Mech 2007; 578: 331-69.

11. Cheng Z, Agranat V, Tchouvelev AV, Houf W, Zhubrin SV. PRD hydrogen release and dispersion; a comparison of CFD results obtained from using ideal and real gas law properties. Proceedings of International Conference on Hydrogen Safety; 2005 Sep 8-10; Pisa, Italy.

12. Mohamed K, Paraschivoiu M. Real gas simulation of hydrogen release from a high-pressure chamber. Int J Hydrog Energy 2005; 30: 903-12.

13. Trepanier JY, Paraschivoiu M, Reggio M, Camarero R. A conservative shock fitting method on unstructured grids. J Comput Phys 1996; 126: 421-33.

14. Zhang XP, Zhou D, Bao Y. Mesh motion approach based on spring analogy method for unstructured meshes. J Shanghai Jiaotong Univ (Sci) 2010; 15: 138-46. 
15. Zenga D, Ethier CR. A semi-torsional spring analogy model for updating unstructured meshes in 3D moving domains. Finite Elem Anal Des 2005; 41: 1118-39.

16. Bragin MV, Makarov DV, Molkov VV. Pressure Limit of Hydrogen Spontaneous Ignition in a Tshaped Channel. International Conference on Hydrogen Safety; 2011; San Francisco, USA.

17. Pedro G, Peneau F, Oshkai P, Djilali N. Computational Analysis of Transient Gas Release from a High Pressure Vessel. Proceedings of CFD Conference; 2006; Kingston, Canada.

18. Ashkenas H, Sherman FS. The Structure and Utilization of Supersonic Free Jets in Low Density Wind Tunnel. Rarefied Gas Dynamics, Fourth Symposium; 1966; 2: 84-105. 


\section{List of Figures}

Figure (1) - Three-dimensional and two-dimensional views of the moving mesh

Figure (2) - Release area expanding for the initial diameter of $1.0 \mathrm{~mm}$ at the rate of $500 \mathrm{~m} / \mathrm{s}$.

Figure (3) - Mach number along the centerline for pressure of $10 \mathrm{MPa}$

(Left: results of [16], Right: present simulation)

Figure (4) - Pressure on the contact surface and contact surface location for two meshes and different opening rates

Figure (5) - Pressure on the contact surface and contact surface location for two meshes and different initial diameters; the pressure is lower and the location of the contact surface is slightly more advanced for the fine mesh results

Figure (6) - Pressure and contact surface location comparison for fine meshes at opening speed of $80 \mathrm{~m} / \mathrm{s}$

Figure (7) - Properties after 3 micro seconds of release for an opening speed of $200 \mathrm{~m} / \mathrm{s}$ and an initial diameter of $1 \mathrm{~mm}$ (Diameter reaches $1.6 \mathrm{~mm}$ at time of 3 micro seconds)

Figure (8) - Properties along the centerline after 3 micro seconds of release for the opening speed of $200 \mathrm{~m} / \mathrm{s}$ and initial diameter of $1 \mathrm{~mm}$

Figure (9) - Pressure on the contact surface and Contact surface location for the initial diameter of $1.0 \mathrm{~mm}$ at different opening rates

Figure (10) - Pressure on the contact surface and contact surface location for different initial diameters at the opening rate of $200 \mathrm{~m} / \mathrm{s}$

Figure (11) - Concentration at the opening rate of $200 \mathrm{~m} / \mathrm{s}$ and initial diameter of $1 \mathrm{~mm}$ 


\section{List of Tables}

Table (1)-Final Mach disk location comparison 


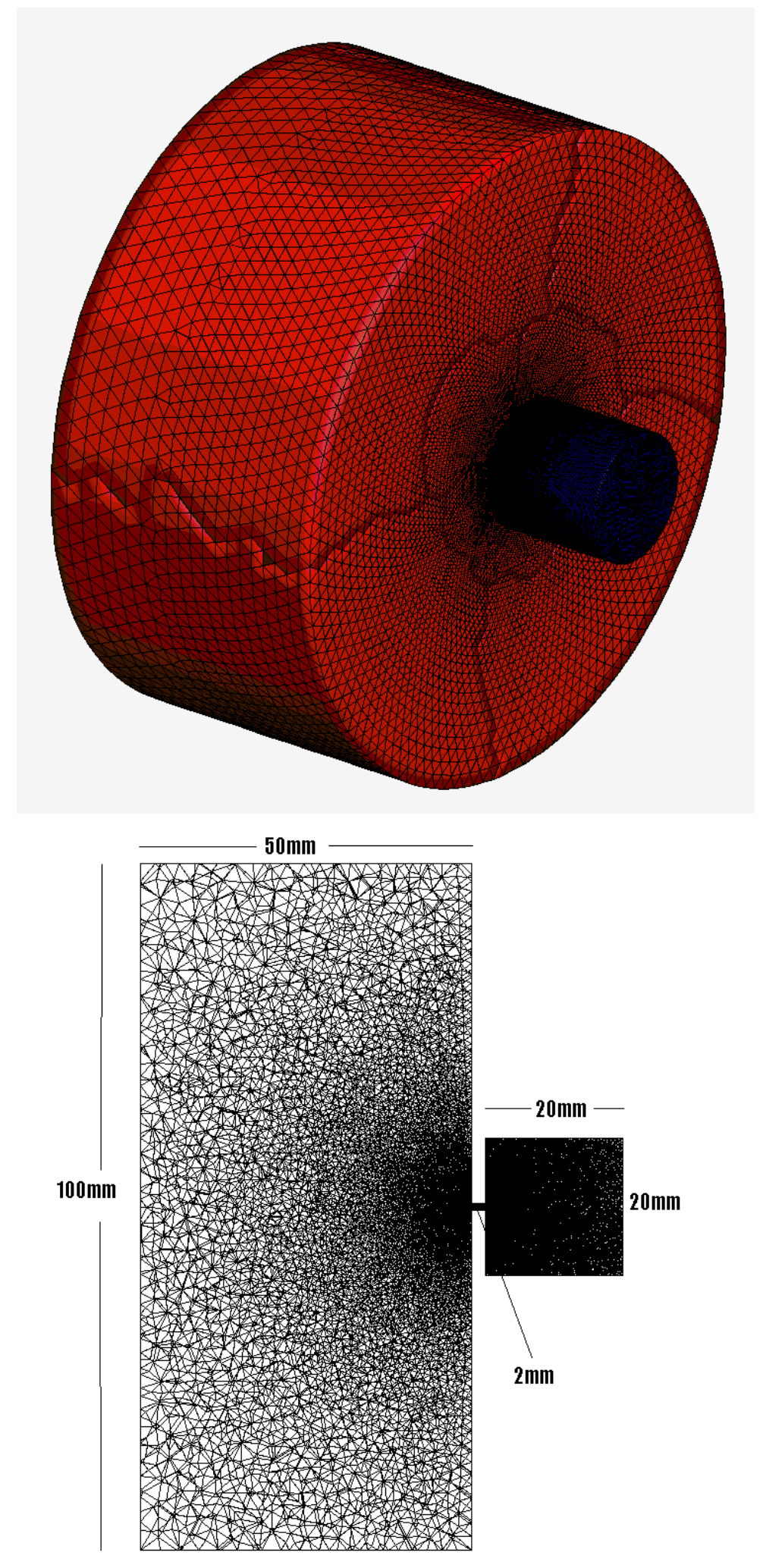

Figure (1) - Three-dimensional and two-dimensional views of the moving mesh 


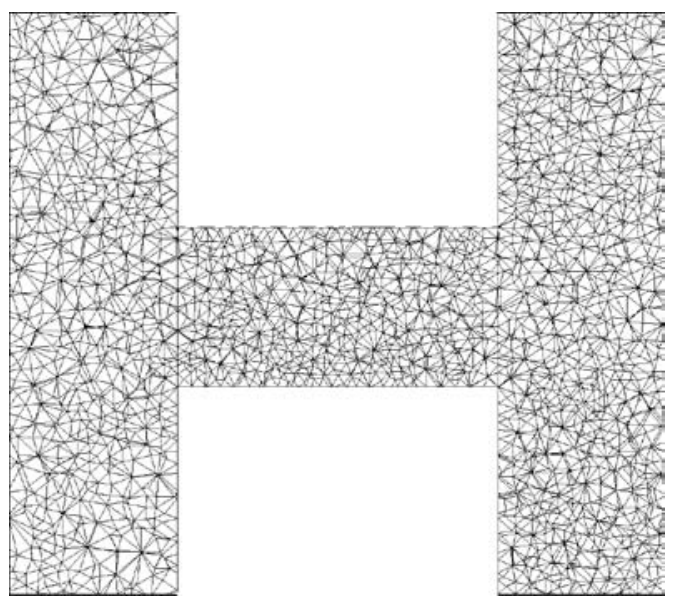

Initial diameter

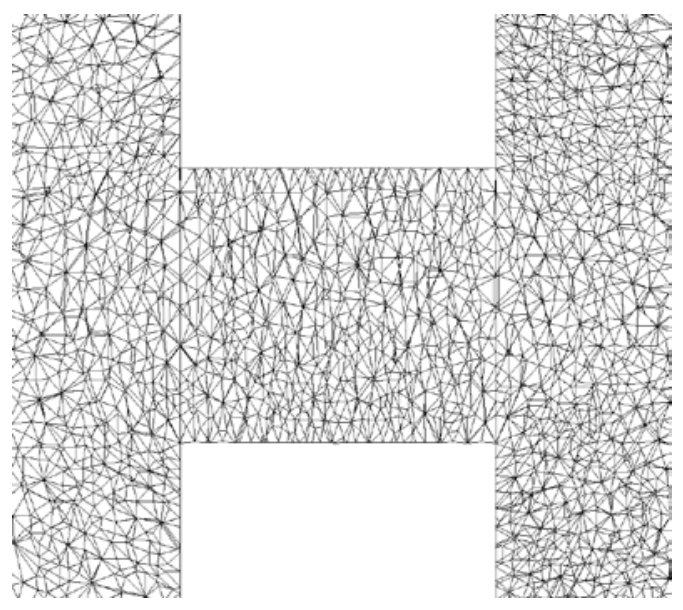

After 1.5 micro seconds

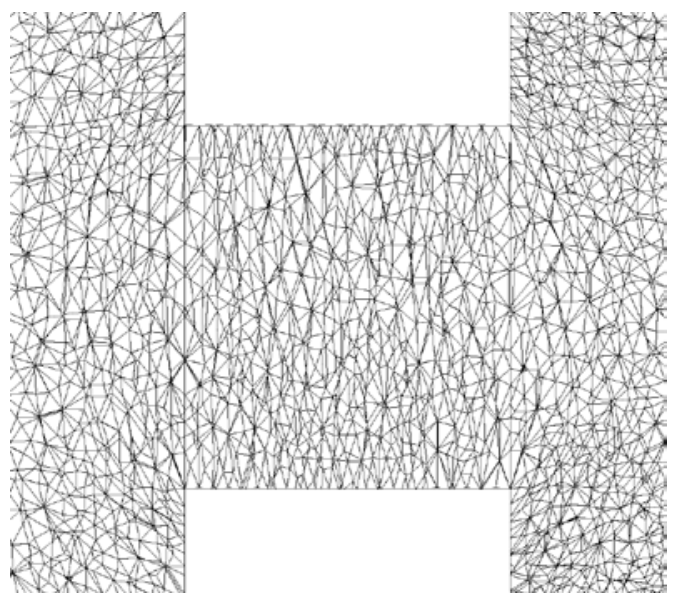

After 2.5 micro seconds

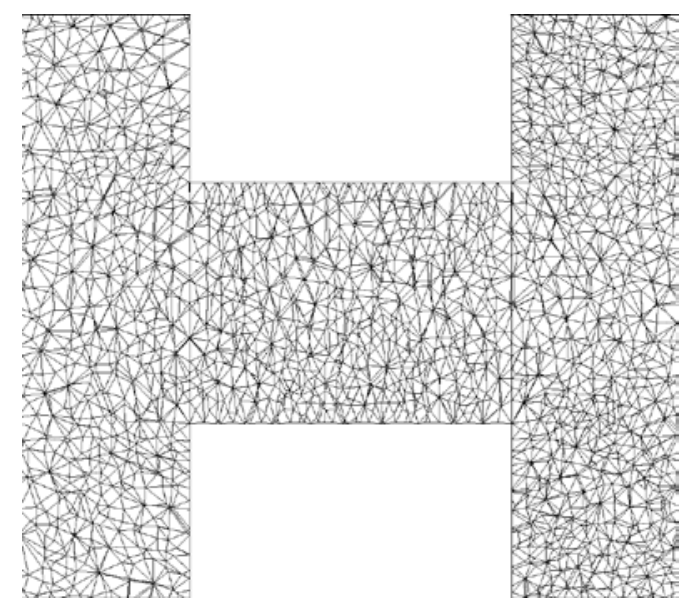

After 1.0 micro seconds

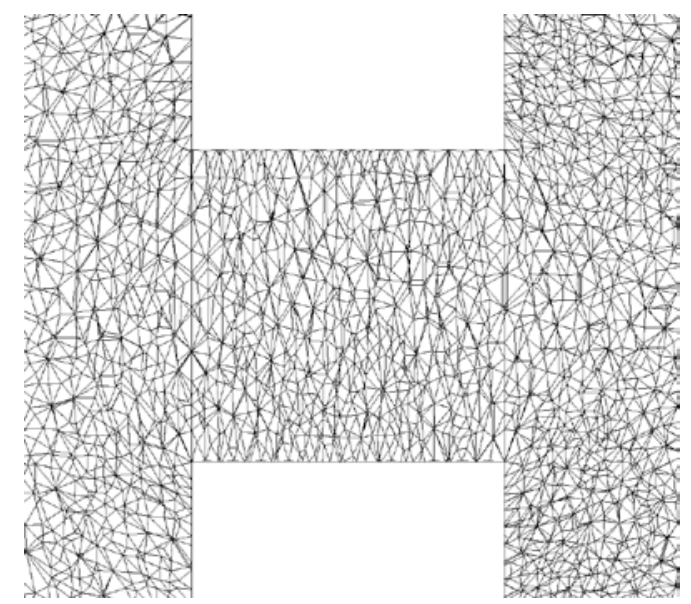

After 2.0 micro seconds

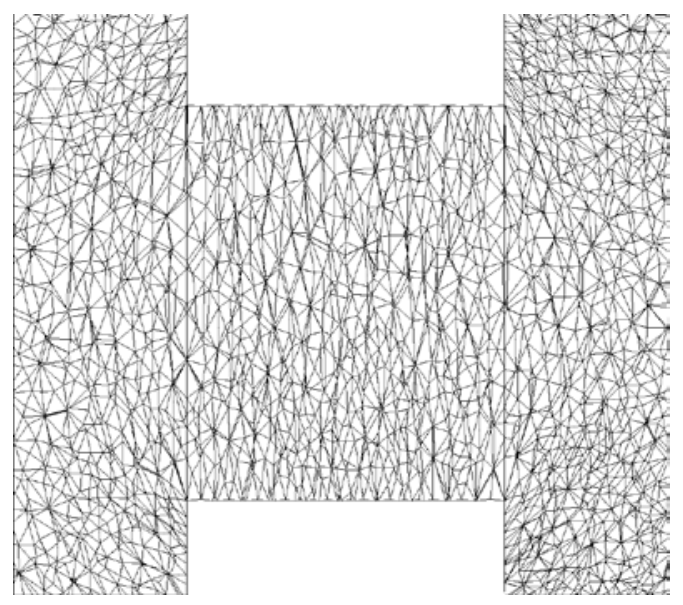

After 3.0 micro seconds

Figure (2) - Release area expanding for the initial diameter of $1.0 \mathrm{~mm}$ at the rate of $500 \mathrm{~m} / \mathrm{s}$. 

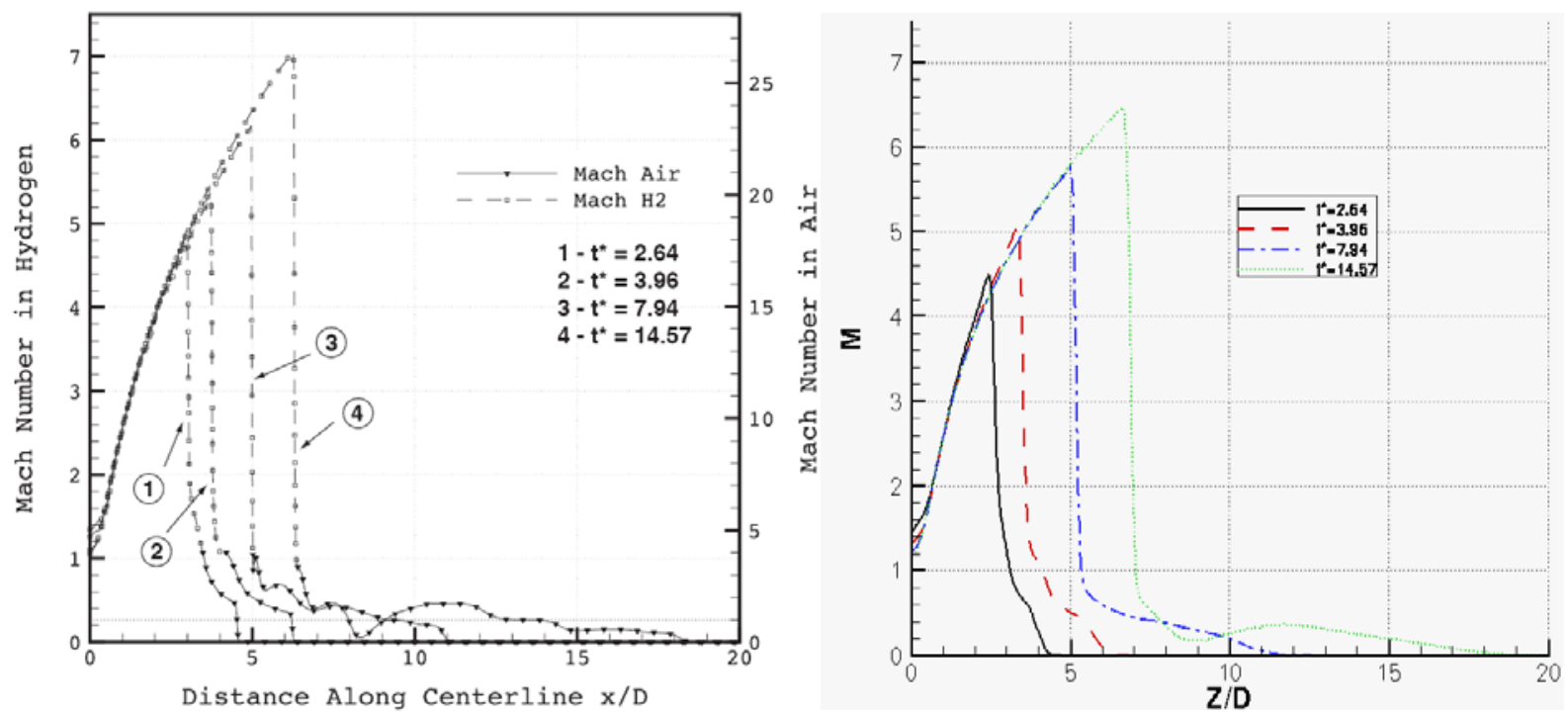

Figure (3) - Mach number along the centerline for pressure of $10 \mathrm{MPa}$ (Left: results of [16], Right: present simulation) 


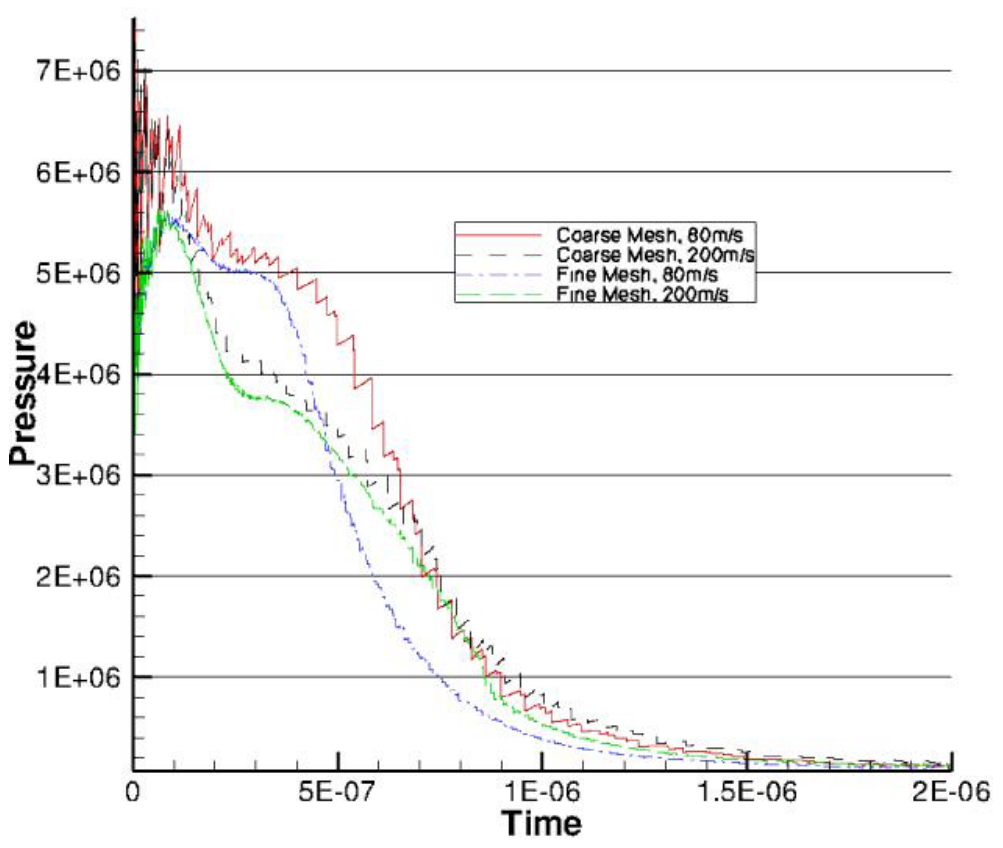

a) Pressure

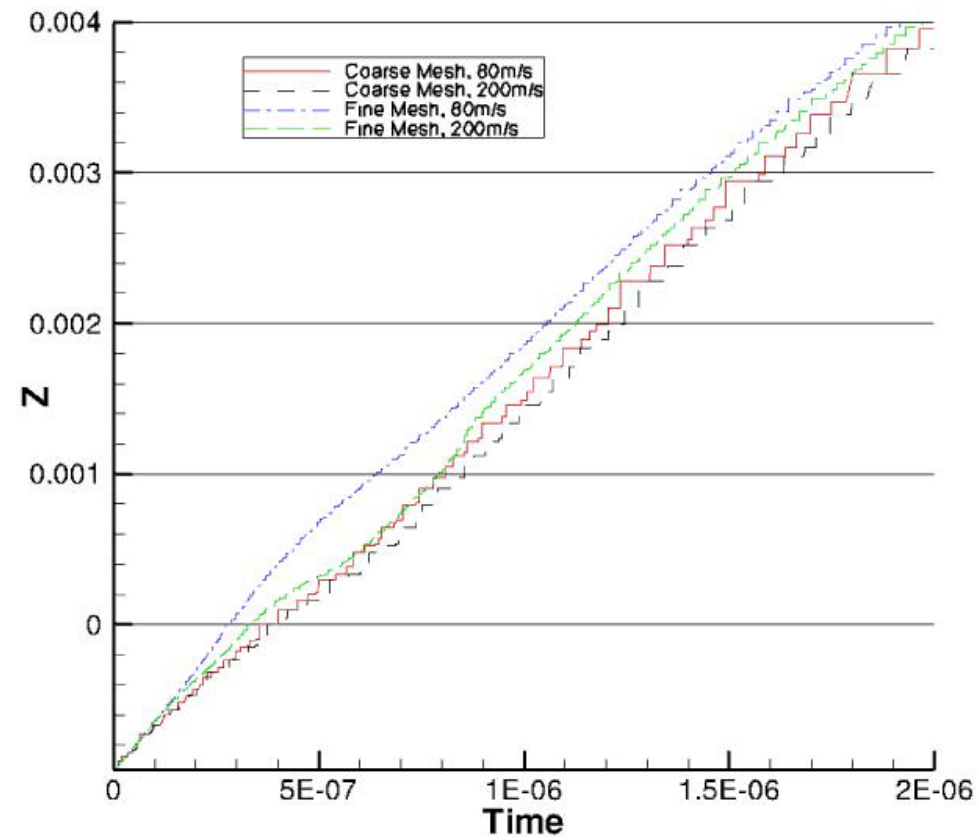

b) Contact Surface Location

Figure (4) - Pressure on the contact surface and contact surface location for two meshes and different opening rates 


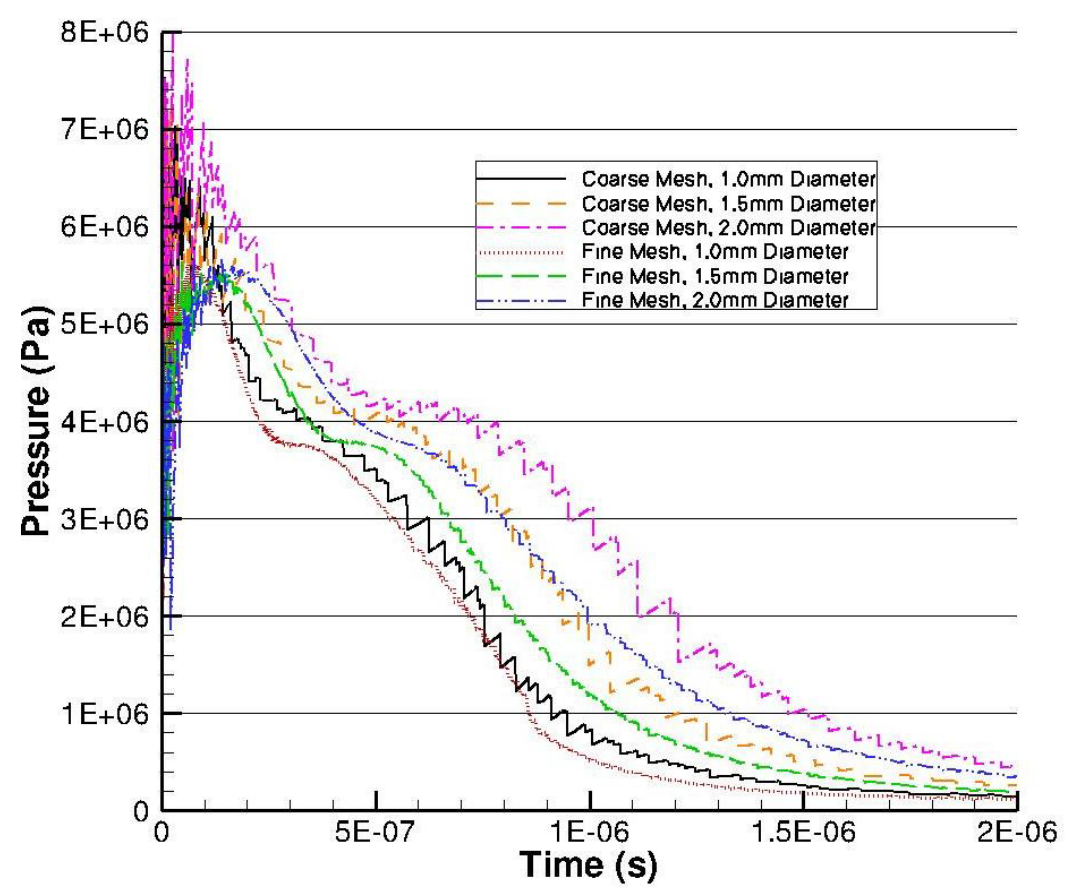

a) Pressure

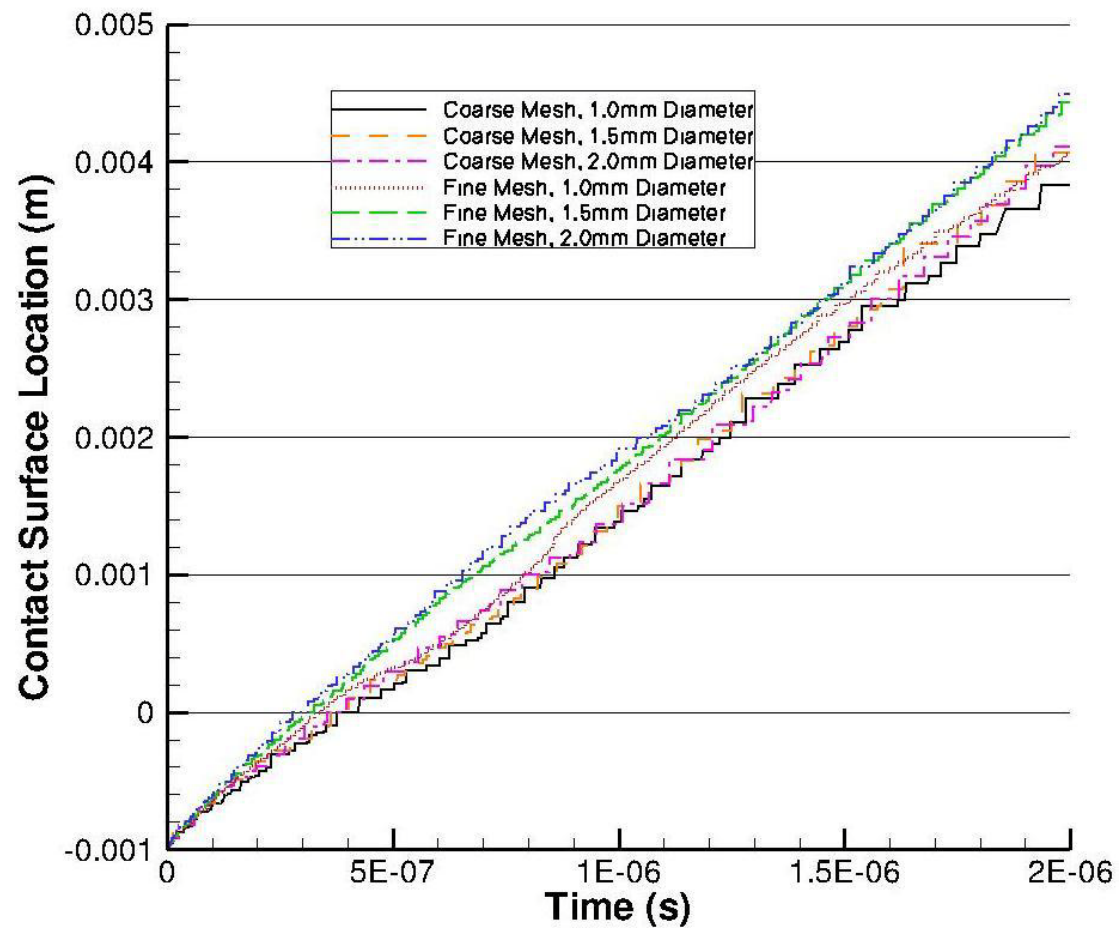

b) Contact Surface Location

Figure (5) - Pressure on the contact surface and contact surface location for two meshes and different initial diameters; the pressure is lower and the location of the contact surface is slightly more advanced for the fine mesh results 


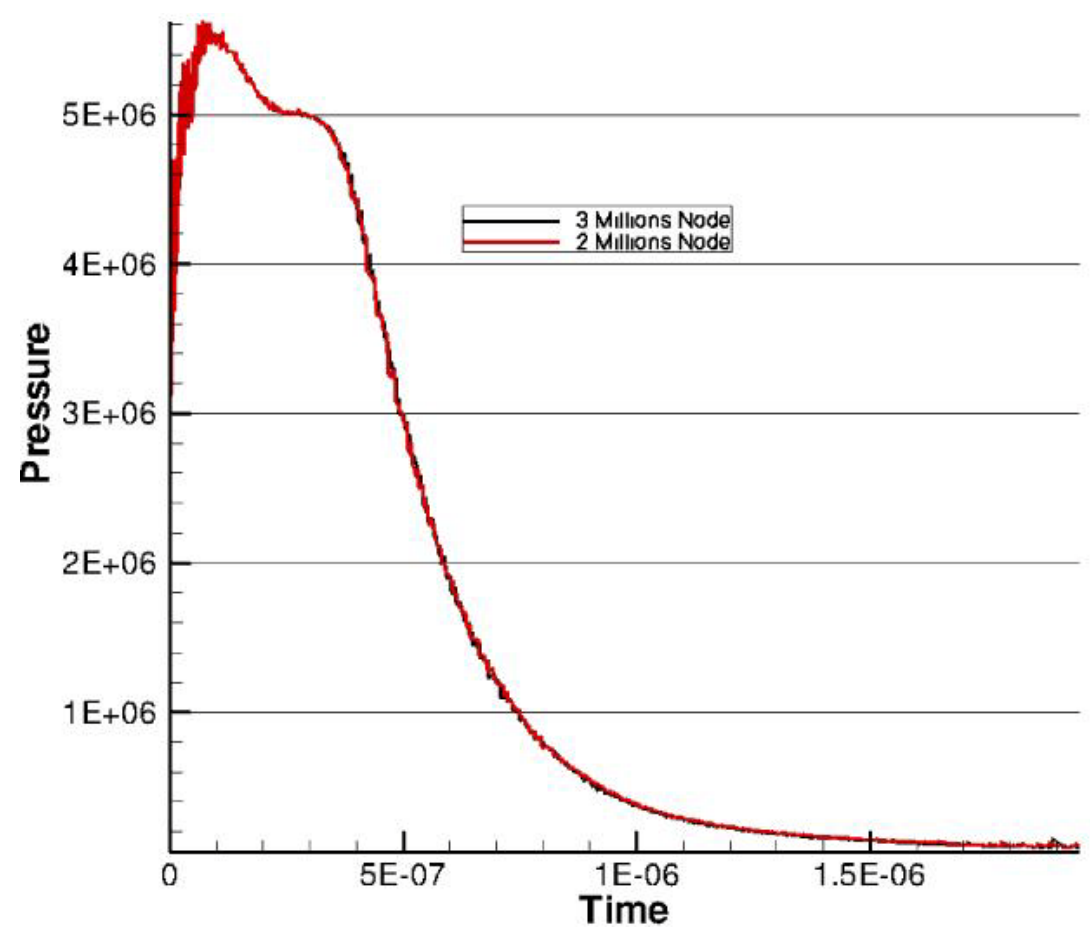

a) Pressure

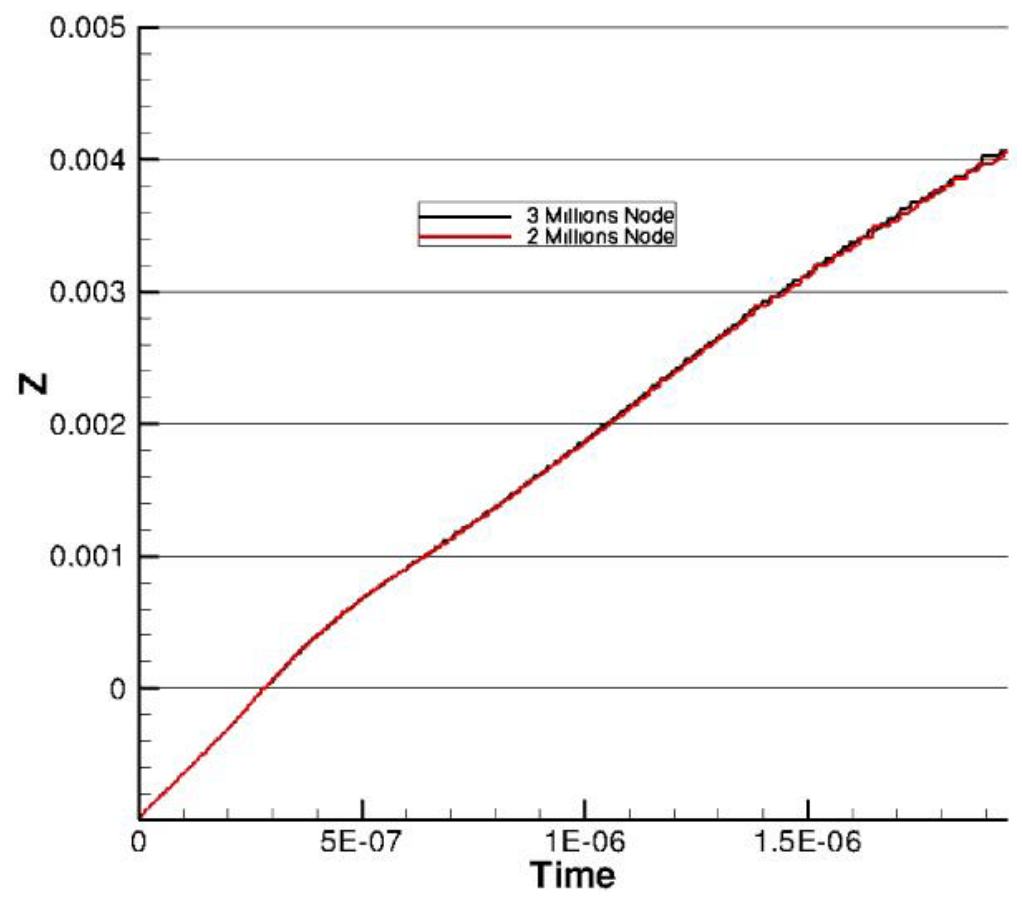

b) Contact Surface Location

Figure (6) - Pressure and contact surface location comparison for fine meshes at opening speed of $80 \mathrm{~m} / \mathrm{s}$ 


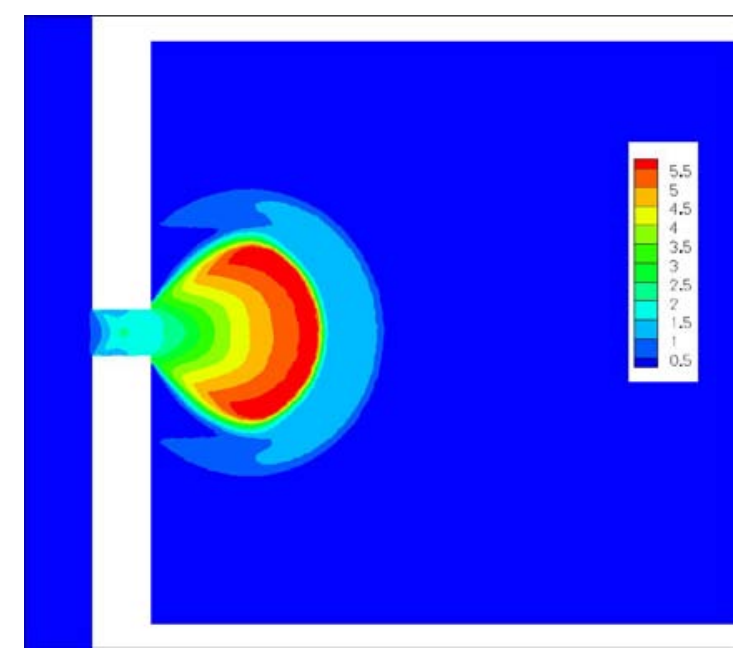

a) Mach Contours

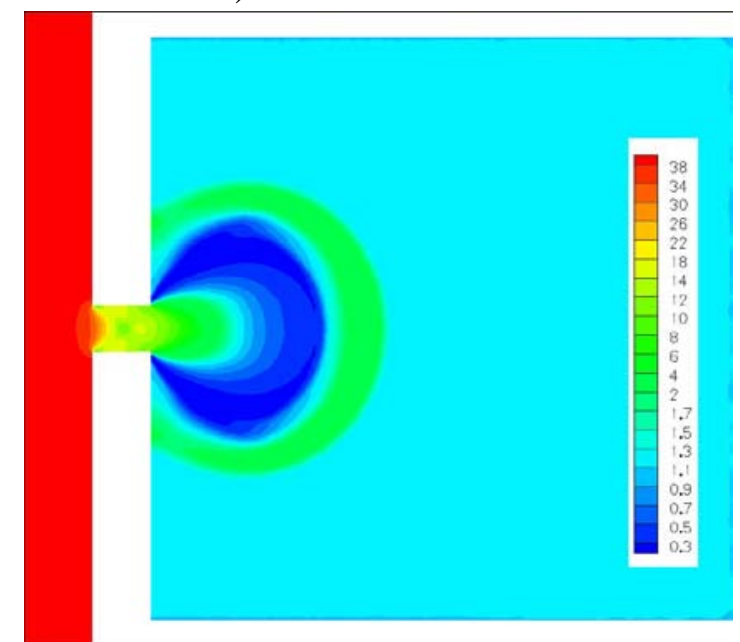

c) Density Contours

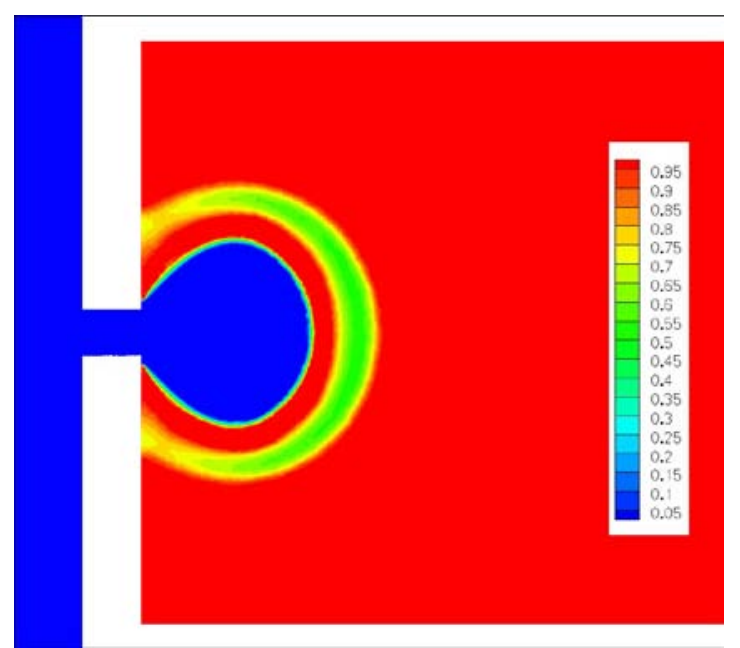

b) Concentration Contours

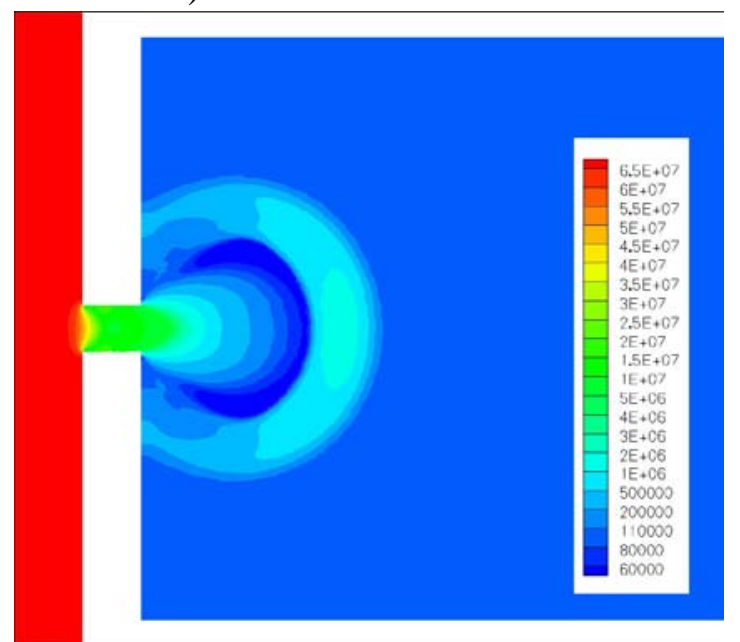

d) Pressure Contours

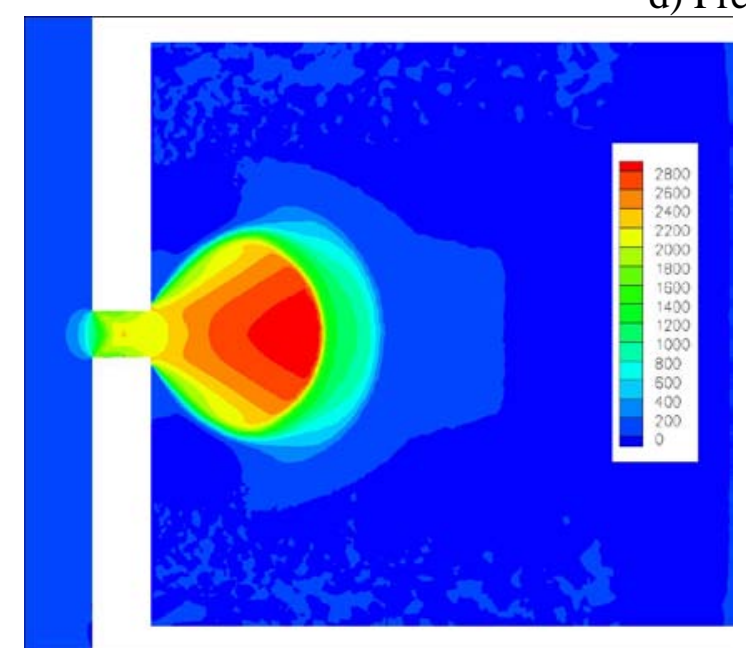

e) Velocity Contours

Figure (7) - Properties after 3 micro seconds of release for an opening speed of $200 \mathrm{~m} / \mathrm{s}$ and an initial diameter of $1 \mathrm{~mm}$ (Diameter reaches $1.6 \mathrm{~mm}$ at time of 3 micro seconds) 


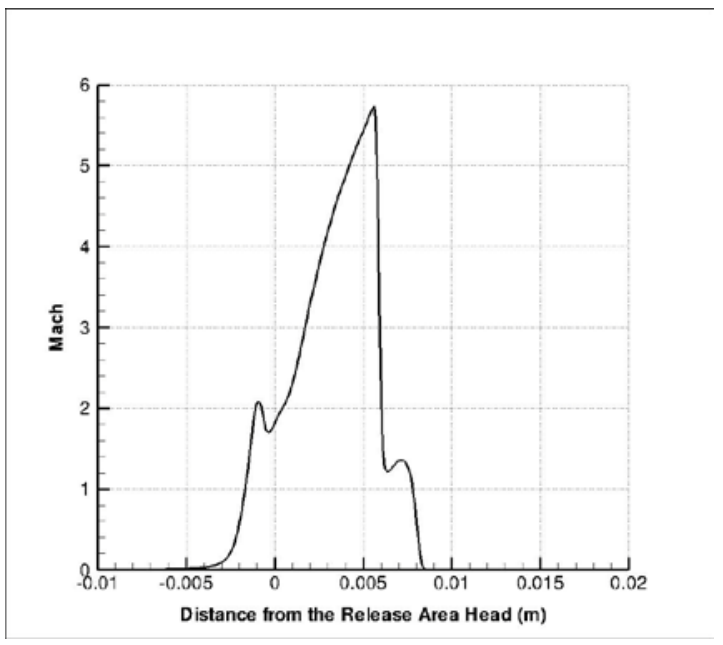

a) Mach Number

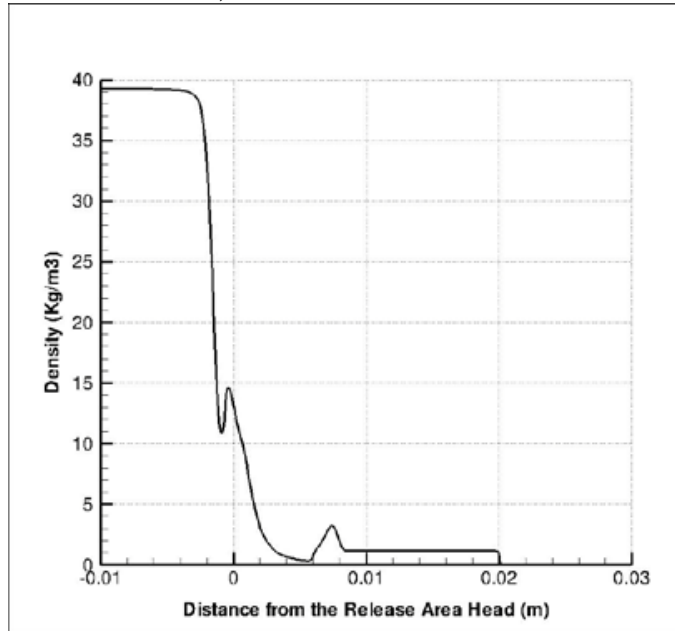

c) Density

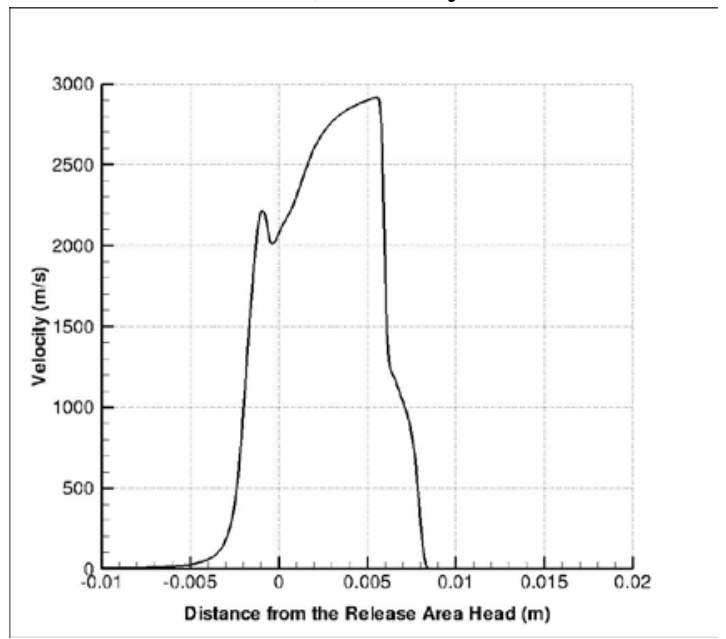

e) Velocity

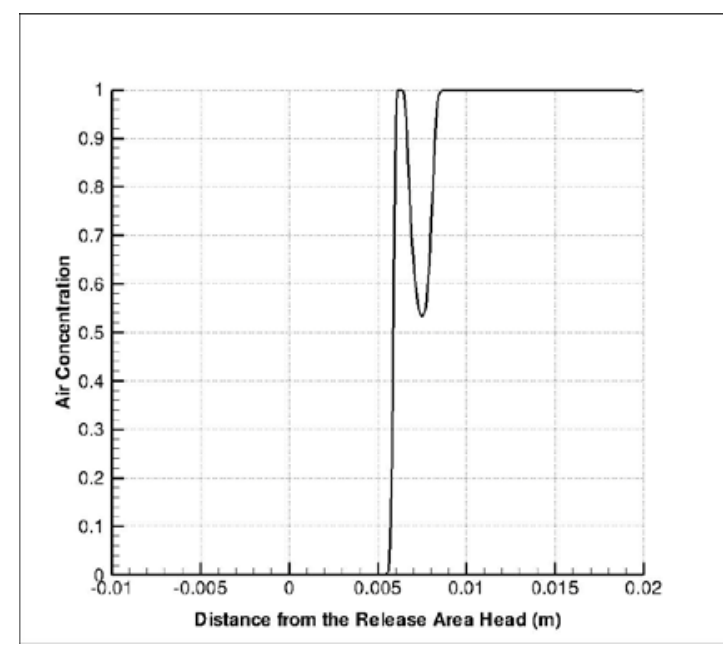

b) Concentration
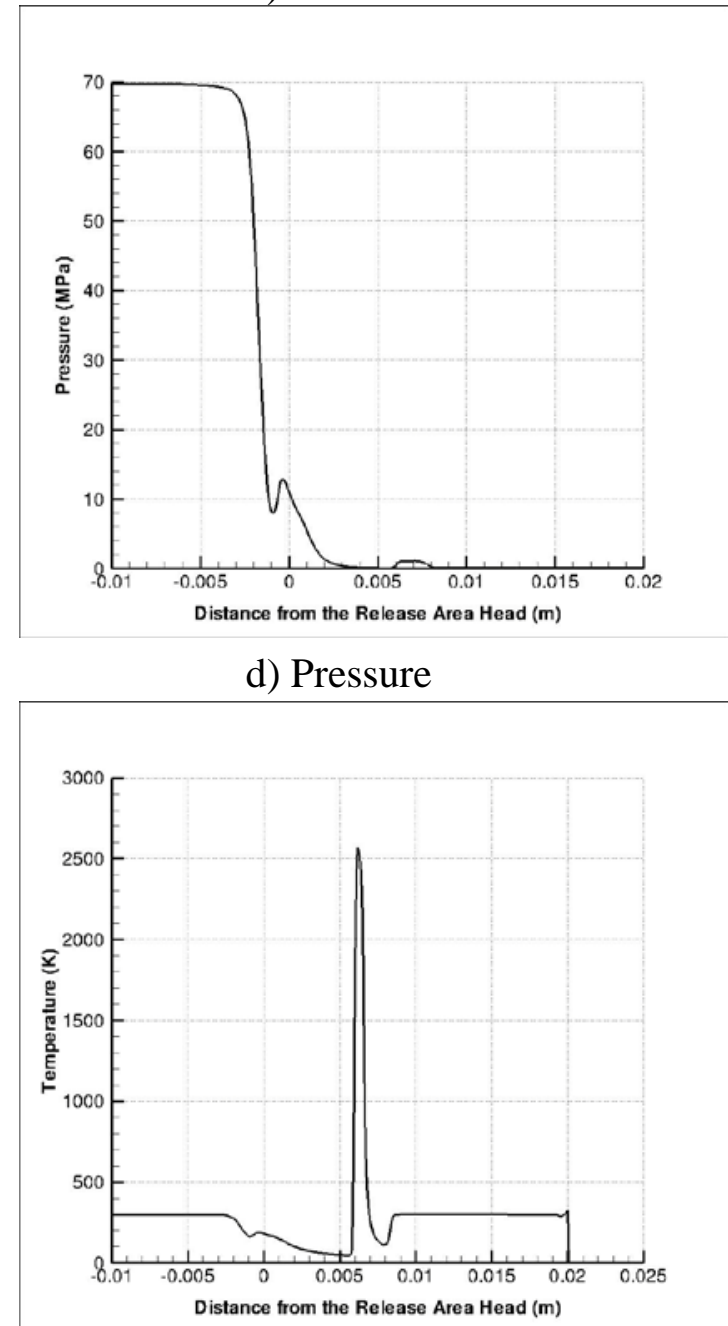

f) Temperature

Figure (8) - Properties along the centerline after 3 micro seconds of release for the opening speed of $200 \mathrm{~m} / \mathrm{s}$ and initial diameter of $1 \mathrm{~mm}$ 


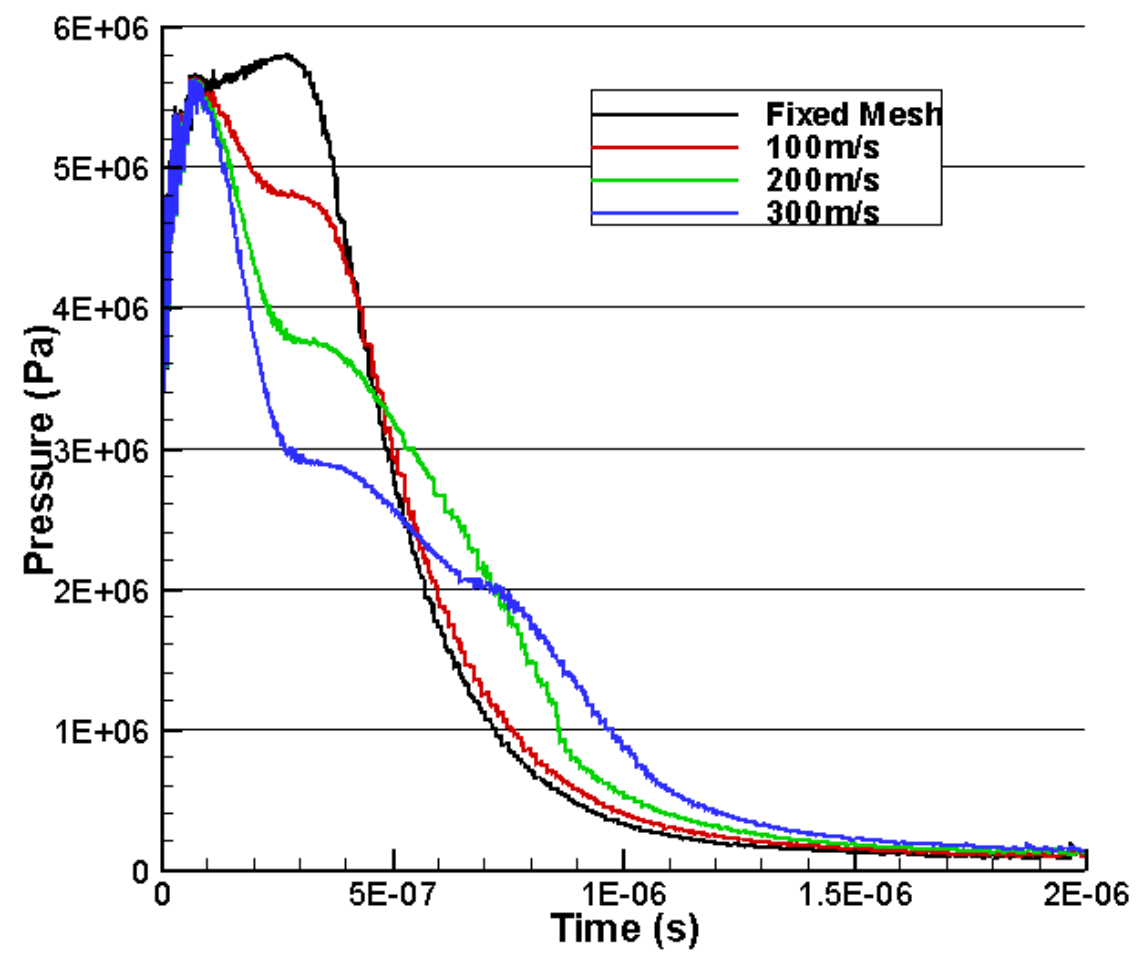

a) Pressure

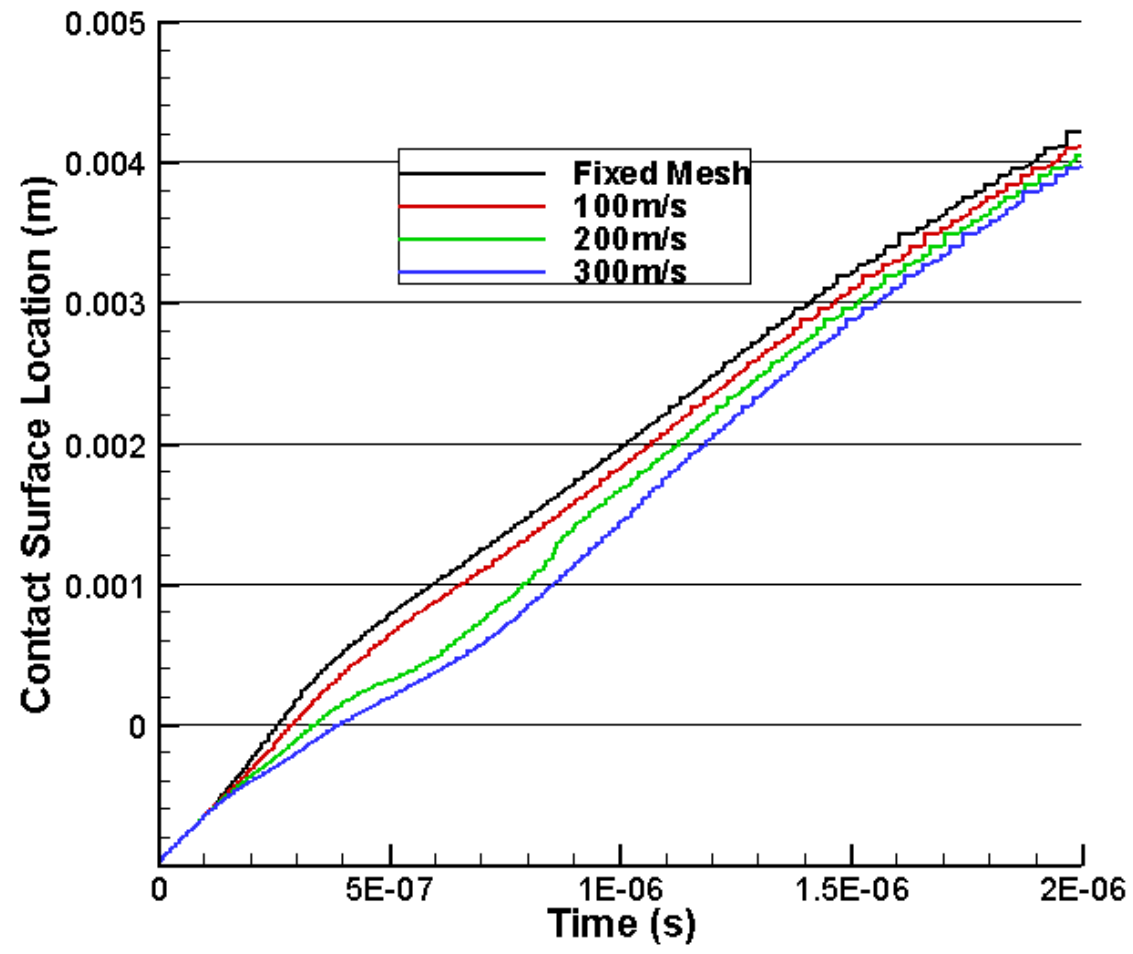

b) Contact Surface Location

Figure (9) - Pressure on the contact surface and contact surface location for the initial diameter of $1.0 \mathrm{~mm}$ at different opening rates 


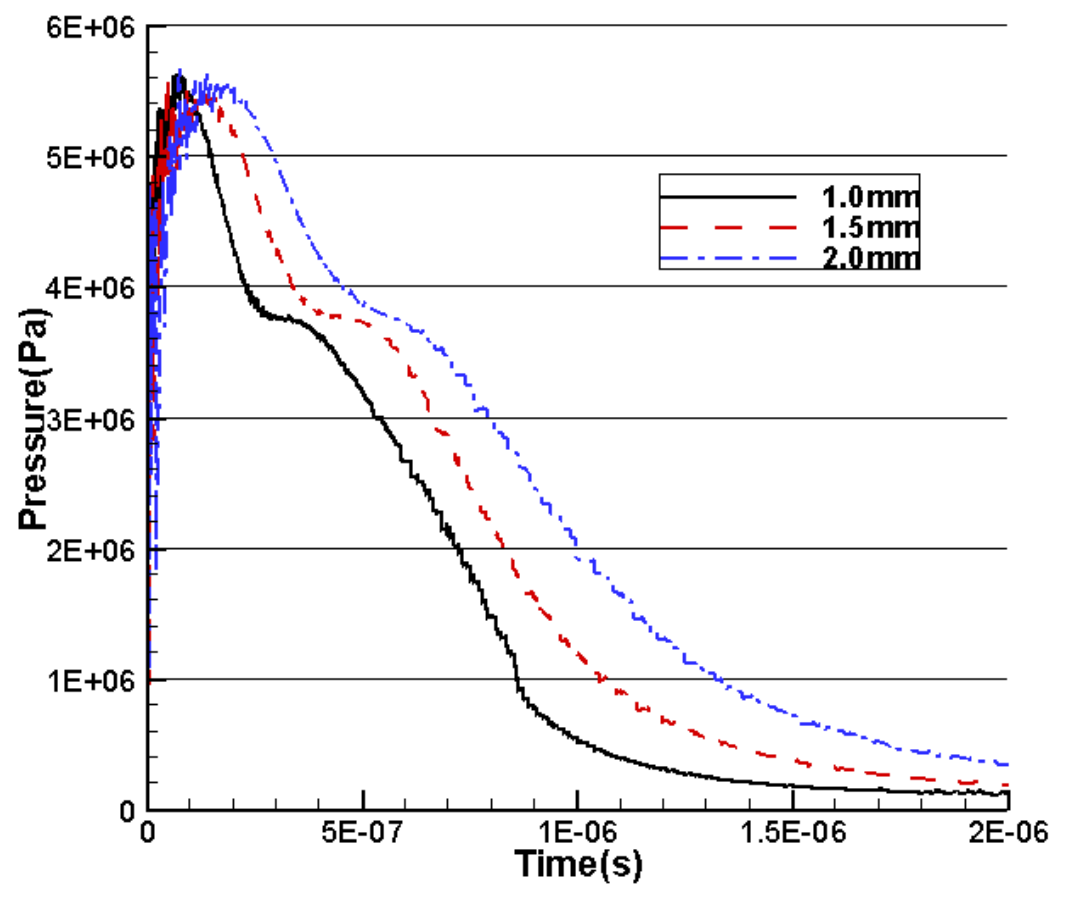

a) Pressure

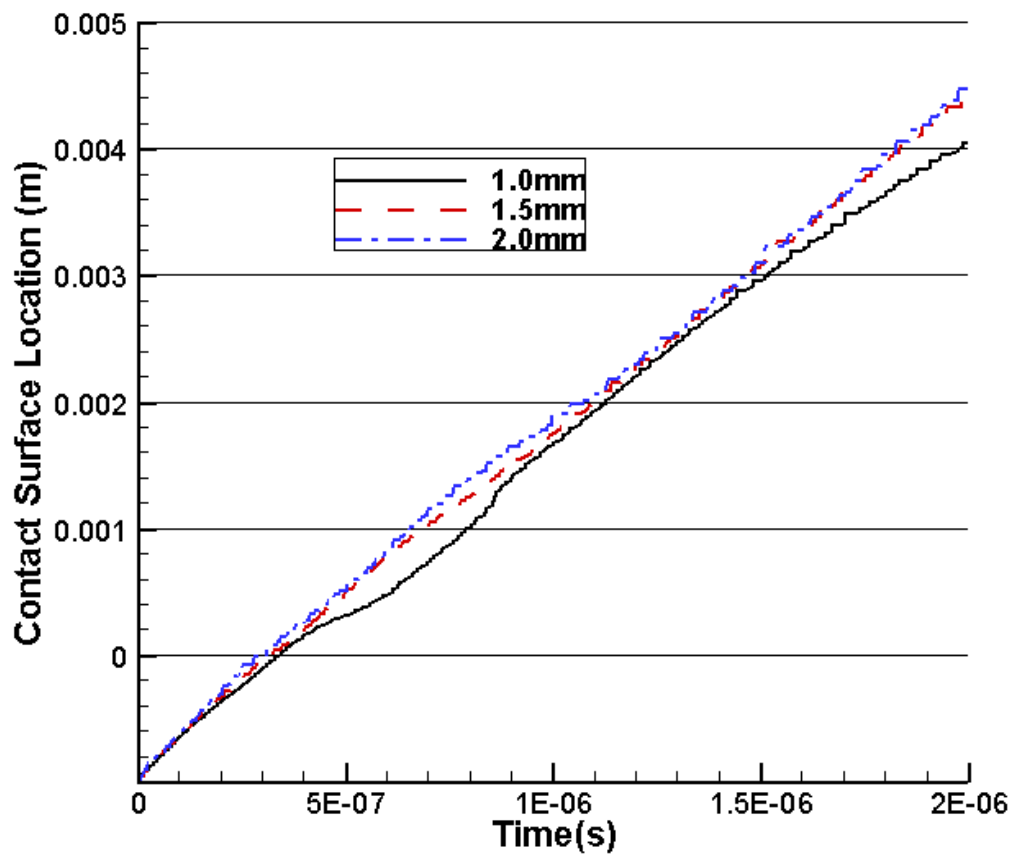

b) Contact Surface Location

Figure (10) - Pressure on the contact surface and contact surface location for different initial diameters at the opening rate of $200 \mathrm{~m} / \mathrm{s}$ 


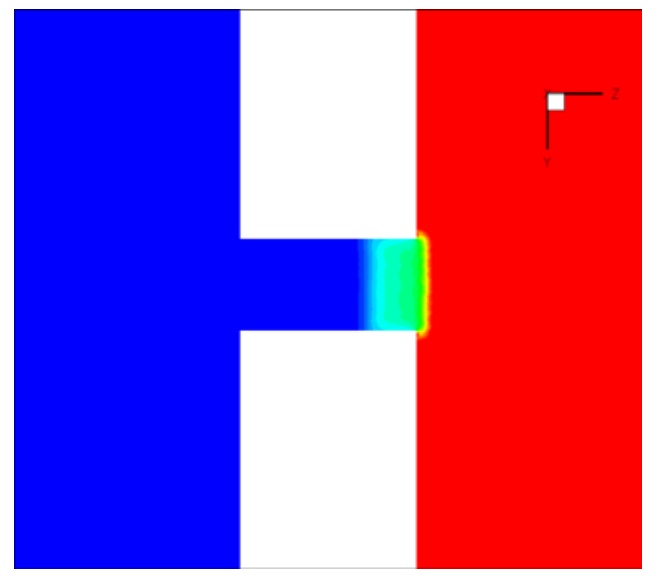

a) After 0.2 micro seconds

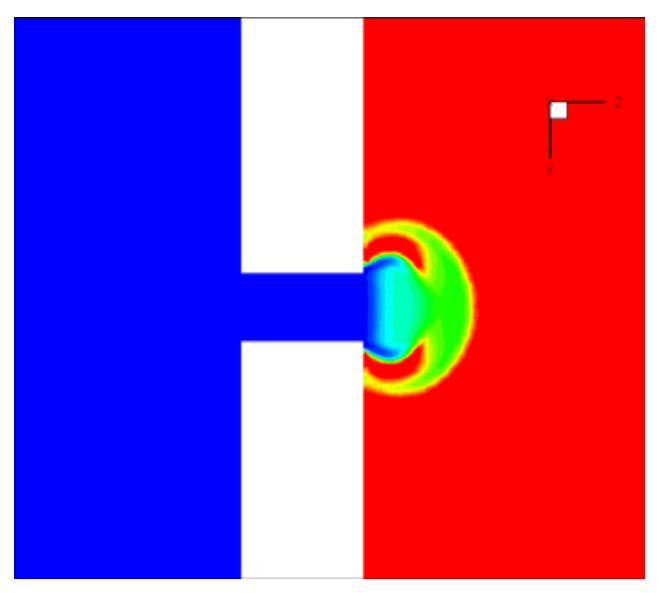

c) After 0.6 micro seconds

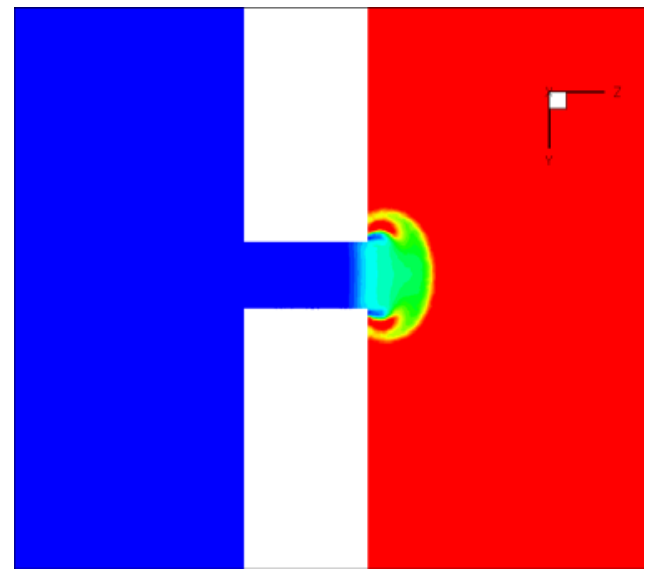

b) After 0.4 micro seconds

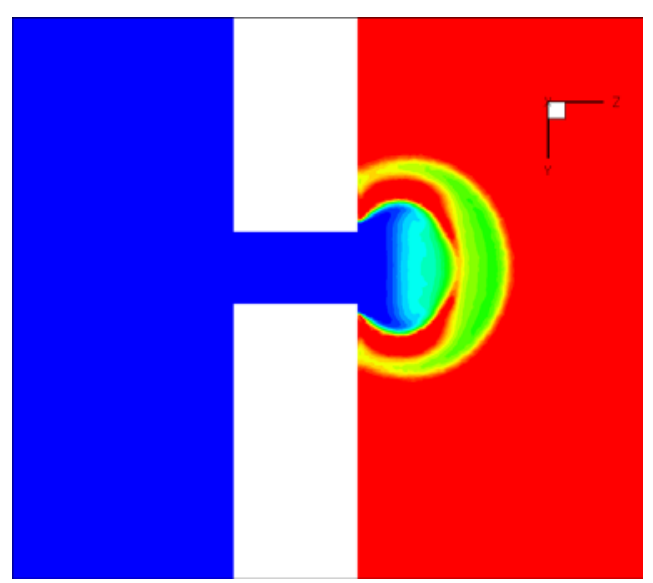

d) After 0.8 micro seconds

Figure (11) - Concentration at the opening rate of $200 \mathrm{~m} / \mathrm{s}$ and initial diameter of $1 \mathrm{~mm}$ 
Table (1)-Final Mach disk location comparison

\begin{tabular}{|l|l|l|l|}
\hline & $10 \mathrm{MPa}$ & $34.5 \mathrm{MPa}$ & $70 \mathrm{MPa}$ \\
\hline$Z / D$ (analytical equation) & 6.66 & 12.36 & 17.61 \\
\hline$Z / D$ (Present Simulation) & 7.00 & 14.00 & 20.00 \\
\hline
\end{tabular}

